\title{
ADVANCES IN THE SOLIDIFICATION OF IN718 AND RS5 ALLOYS
}

\author{
L. Nastac ', J. J. Valencia ${ }^{2}$, M. L. Tims ${ }^{2}$, and F. R. Dax ${ }^{1}$ \\ ${ }^{1}$ Concurrent Technologies Corporation, $4256{ }^{\text {th }}$ Avenue, Regional Enterprise Tower, $28^{\text {th }}$ Floor, \\ Pittsburgh, PA 15219 \\ ${ }^{2}$ Concurrent Technologies Corporation, 100 CTC Drive, Johnstown, PA 15904-1935
}

\begin{abstract}
One of the main objectives of this work is to analyze and compare the solidification characteristics of $\mathrm{N} 718$ and RS5 alloys. In this regard, a methodological approach for estimation of the solidification parameters of multicomponent alloy systems was developed. The methodology is based on a deterministic solidification-kinetics approach for multicomponent and pseudo-binary alloy systems. Comparisons between IN718 and RS5 alloys in terms of solidification morphologies are provided. Calculated and experimental results for as-cast microstructures obtained with the Thermally Controlled Solidification process that was developed by PCC Inc. is presented. The withdrawal rate effects on the solidification microstructures of IN718 and RS5 are discussed in detail. Differential thermal analysis (DTA) analysis and metallurgical characterization were also performed to determine the solidification and post-solidification phases and to estimate the secondary dendrite arm spacing in RS5 alloy. Solidification maps were predicted for IN718 and RS5 alloy.
\end{abstract}

\section{Introduction}

An NCEMT project was developed by Concurrent Technologies Corporation (CTC) to optimize manufacturing methods for production of expansive $(20 \mathrm{~mm} \times 2000 \mathrm{~mm})$, thin wall (about $1 \mathrm{~mm}$ ) structural castings of Ni-based superalloys. Thermally Controlled Solidification (TCS) process developed by PCC Structurals, Inc. (PCC) of Portland, OR, was selected for casting of a diffuser/combuster casing for the $\mathrm{AE} 1107 \mathrm{C}$ engine used on the $\mathrm{V}-22$ Osprey Helicopter. IN718 and RS5 Ni-based superalloys were identified as promising choices for the casing because of their high-temperature mechanical properties. The present paper evaluates and compares the solidification characteristics of IN718 and RS5 alloys. Several experimental results to confirm some of the predictions shown in this paper were performed by using the vacuum induction melting (VIM) at CTC (Fig. 1). Some of results were used to estimate the solidification properties of RS5 and IN718 alloys, work that is crucial in determining the solidification characteristics and their related defects. A methodology previously developed [13] was applied to calculate these parameters. This paper summarizes some of the efforts in estimating these solidification parameters, including prediction of the as-cast microstructure.

\footnotetext{
Superalloys $718,625.706$ and Various Derivatives Edited by E.A. Loria

TMS (The Minerals, Metals \& Materials Society), 2001
} 


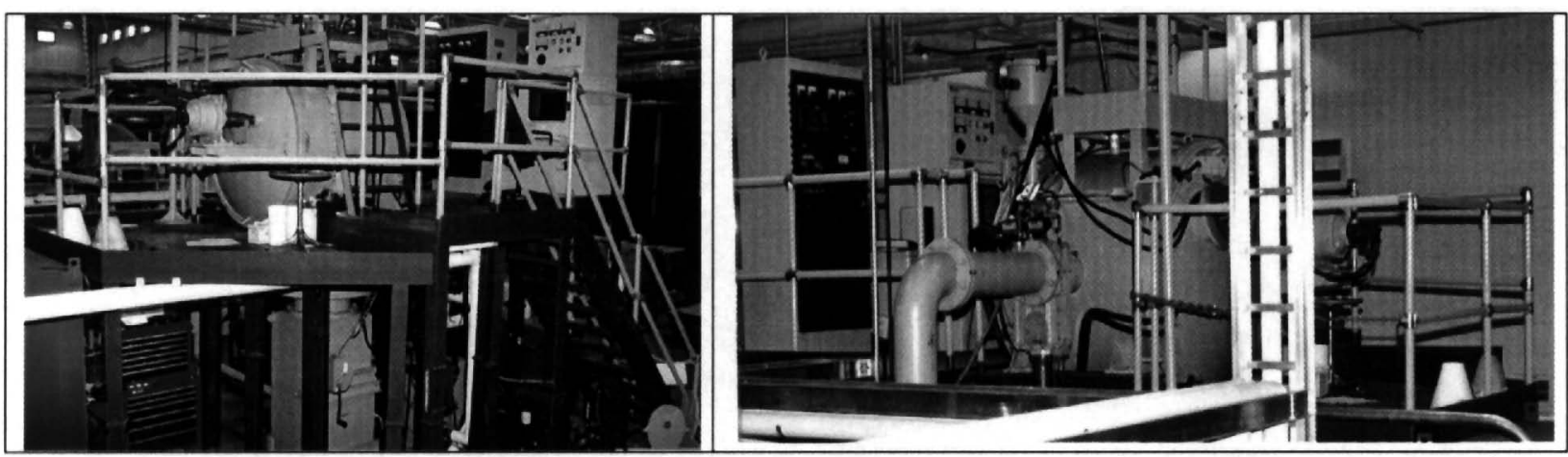

Figure 1: VIM Furnace at CTC (the withdrawal velocity can vary from $1 \mathrm{in} / \mathrm{hr}$ to $60 \mathrm{in} / \mathrm{min}$ ).

\section{Development of Solidification Properties of IN718 and RS5 Alloys}

The methodology for calculating solidification properties consists of three steps [1-3]: (1) first, the liquidus slopes and partition coefficients are either extracted from binary phasediagrams for Ni-X alloys or computed [1-4], or estimated from experimental measurements [1, 2]; (2) then, assuming weak or no interaction between each of the $X$ elements, the solidification parameters based on a multicomponent approach are computed; and (3) finally, an easy-to-apply pseudo-binary which that successfully replaces the multicomponent approach [1-3] is applied.

\section{Solidification Parameters}

Liquidus slopes and distribution coefficients for RS5 and N718 alloys are presented in Tables II and III, respectively, where the chemical composition of these alloys is shown in Table I [3]. The bold-highlighted elements in Table II and III would have strong influence on the solidification characteristics of these alloys ( $\mathrm{Ti}$ and $\mathrm{Nb}$ being the most significant).

Table I Chemical composition of RS5 and IN718 alloys

\begin{tabular}{|c|c|c|c|c|c|c|c|c|c|c|c|c|}
\hline Chemistry & $\mathrm{Ni}$ & $\mathrm{C}$ & $\mathrm{Cr}$ & $\mathrm{Co}$ & $\mathrm{Al}$ & $\mathrm{Ti}$ & $\mathrm{Nb}$ & $\mathrm{Ta}$ & $\mathrm{W}$ & $\mathrm{Mo}$ & $\mathrm{Si}$ & $\mathrm{Fe}$ \\
\hline RS5 & 56.85 & 0.084 & 16.14 & 10.16 & 0.93 & 2.73 & 4.86 & 1.49 & 2.01 & 4.82 & 0.053 & 0.065 \\
\hline IN718 & 53.23 & 0.056 & 18.61 & 0.14 & 0.44 & 0.82 & 4.96 & 0.01 & 0.0 & 2.93 & 0.07 & 18.72 \\
\hline
\end{tabular}

Table II Liquidus slopes and distribution coefficients of RS5 alloys

\begin{tabular}{|c|c|c|c|c|c|c|c|c|c|c|c|c|}
\hline Properties & $\mathrm{Ni}$ & $\mathrm{C}$ & $\mathbf{C r}$ & $\mathbf{C o}$ & $\mathbf{A l}$ & $\mathbf{T i}$ & $\mathbf{N b}$ & $\mathbf{T a}$ & $\mathrm{W}$ & $\mathbf{M o}$ & $\mathrm{Si}$ & $\mathrm{Fe}$ \\
\hline $\mathrm{m}_{\mathrm{L}}$ & 0 & -10.0 & -1.91 & 3.72 & -14.1 & -17.3 & -9.0 & -5.0 & -0.87 & -5.49 & 0.0 & -0.141 \\
\hline $\mathrm{k}_{0}$ & 1 & 0.25 & 1.19 & 1.4 & 0.68 & 0.52 & 0.35 & 0.68 & 1.46 & 0.78 & 0.48 & 1.16 \\
\hline $\mathrm{m}_{\mathrm{l}} \mathrm{C}_{1}\left(1-\mathrm{k}_{0}\right) \mathrm{k}_{0}$ & 0 & -2.52 & $\mathbf{4 . 9 2}$ & $\mathbf{- 1 0 . 8}$ & $\mathbf{- 6 . 1 7}$ & $\mathbf{- 4 3 . 6}$ & $\mathbf{- 8 1 . 2}$ & $\mathbf{- 3 . 5}$ & 0.55 & $\mathbf{- 7 . 4 6}$ & 0.0 & 0.001 \\
\hline
\end{tabular}

Table III Liquidus slopes and distribution coefficients of IN718 alloy

\begin{tabular}{|c|c|c|c|c|c|c|c|c|c|c|c|c|}
\hline Properties & $\mathrm{Ni}$ & $\mathrm{C}$ & $\mathbf{C r}$ & $\mathrm{Co}$ & $\mathbf{A l}$ & $\mathrm{Ti}$ & $\mathbf{N b}$ & $\mathrm{Ta}$ & $\mathrm{W}$ & $\mathbf{M o}$ & $\mathrm{Si}$ & $\mathrm{Fe}$ \\
\hline $\mathrm{m}_{\mathrm{L}}$ & 0 & -10.0 & -1.91 & 3.72 & -13.9 & -21.1 & -9.9 & -4.74 & -0.87 & -5.49 & 0.0 & -0.141 \\
\hline $\mathrm{k}_{0}$ & 1 & 0.25 & 1.19 & 1.4 & 0.68 & 0.24 & 0.35 & 0.55 & 1.46 & 0.78 & 0.48 & 1.16 \\
\hline $\mathrm{m}_{1} \mathrm{C}_{1}\left(1-\mathrm{k}_{0}\right) / \mathrm{k}_{0}$ & 0 & -1.68 & $\mathbf{5 . 6 8}$ & -0.15 & $\mathbf{- 2 . 8 8}$ & $\mathbf{- 5 4 . 8}$ & $\mathbf{- 9 1 . 2}$ & -0.04 & 0.0 & $\mathbf{- 4 . 5 4}$ & 0.0 & 0.368 \\
\hline
\end{tabular}

The equivalent liquid concentration $\left(\bar{C}_{L}\right)$, liquidus slope $\left(\bar{m}_{L}\right)$, and partition coefficient $(\bar{k})$ are defined as follows $[1-3,5]$ :

$$
\bar{C}_{L}=\sum_{i=1}^{n} C_{L}^{i} \quad \bar{m}_{L}=\frac{\sum_{i=1}^{n}\left(m_{L}^{i} C_{L}^{i}\right)}{\bar{C}_{L}} \quad \bar{k}=\frac{\sum_{i=1}^{n}\left(m_{L}^{i} C_{L}^{i} k_{i}\right)}{\sum_{i=1}^{n}\left(m_{L}^{i} C_{L}^{i}\right)}
$$


where $C_{L}^{i}$ is the liquid concentration for element $i$ and is calculated with a microsegregation model $[1,2]$. The liquidus and solidus temperatures for a pseudo-binary system are calculated with:

$$
T_{L}=T_{M}+\bar{m}_{L} \bar{C}_{o} \quad \text { and } \quad T_{S}=T_{M}+\bar{m}_{L} \bar{C}_{f}
$$

where $T_{M}$ is the melting point of pure nickel and $\bar{C}_{o}$ and $\bar{C}_{f}$ are the initial and final values of $\bar{C}_{L}$ computed with Eq. (1). The solidification parameters calculated with Eqs. (1) and (2) are presented in Table IV and Figure 2. The calculated solidification interval is larger for RS5 than for IN718 alloy. The overall constitutional undercooling parameter (see the last column in Table IV) of RS5 is about twice that of IN718 alloy, meaning that RS5 might be more susceptible than IN718 to the formation of solidification-related defects. Also, for similar solidification conditions, the amount of Eutectic-Laves phase is slightly higher in RS5 alloy than in IN718 alloy (see Fig. 2).

Table IV Solidification parameters of RS5 and IN718 alloys

\begin{tabular}{|c|c|c|c|c|c|c|}
\hline Alloy Type & $\mathrm{T}_{\mathrm{L} .}\left({ }^{\circ} \mathrm{C}\right)$ & $\mathrm{T}_{\mathrm{S}}\left({ }^{\circ} \mathrm{C}\right)$ & $\overline{\mathrm{C}}_{\mathrm{L}}$ & $\overline{\mathrm{m}}_{\mathrm{L}}$ & $\overline{\mathrm{k}}$ & $\overline{\mathrm{m}}_{\mathrm{L}} \overline{\mathrm{C}}_{\mathrm{L}}(1-\overline{\mathrm{k}}) / \overline{\mathrm{k}}$ \\
\hline RS5 & 1322.3 & 1166.4 & 43.14 & -3.00 & 0.46 & -151.9 \\
\hline IN718 & 1325.1 & 1194.2 & 46.76 & -2.71 & 0.65 & -68.2 \\
\hline
\end{tabular}

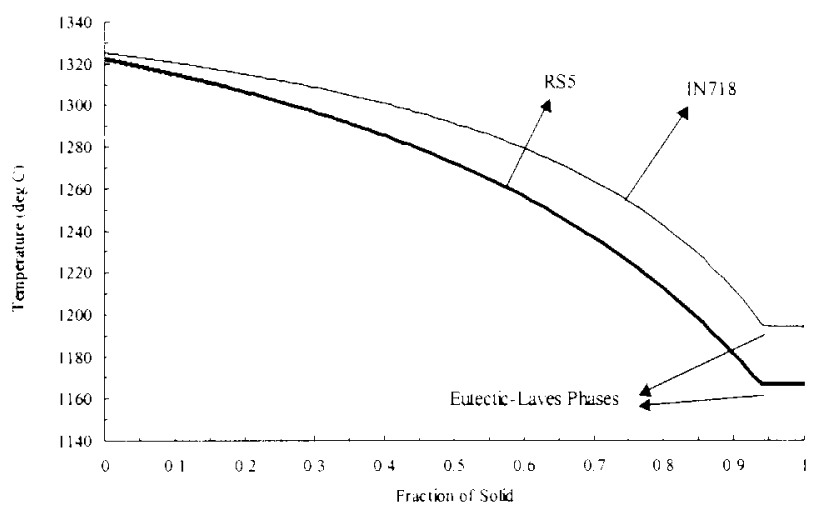

Figure 2: Predicted temperature versus fraction of solid in RS5 and IN718 Cast Alloys.

\section{Microstructural-Kinetics Parameters}

The equiaxed $\left(\bar{\mu}_{E}\right)$ and columnar $\left(\bar{\mu}_{C}\right)$ growth coefficients can be calculated with $[1,2]$ :

$$
\bar{\mu}_{E}=2 \sigma^{*}\left\{\bar{\Gamma}\left[\frac{\bar{m}_{L}(\bar{k}-1) \bar{C}_{L}}{\bar{D}_{L}}+\frac{\rho L}{K_{L}}\right]\right\}^{-1} \quad \bar{\mu}_{C}=\frac{\bar{D}_{L}}{\pi^{2} \bar{\Gamma} \bar{m}_{L}\left(\bar{C}_{o}-\bar{C}_{f}\right) \bar{k}}
$$

where $\sigma^{*}$ is the morphological stability constant of the order of $(2 \pi)^{-2}, \Gamma$ is the Gibbs-Thomson coefficient, $\rho$ is the alloy density, $L$ is the latent heat of fusion, $\bar{D}_{L}$ is the liquid diffusivity, and $K_{L}$ is the liquid thermal conductivity. The primary dendrite arm spacing (PDAS), $\lambda_{l}$, is:

$$
\bar{\lambda}_{1}=\bar{\mu}_{p} V^{-1 / 4} G^{-1 / 2} \quad \text { with } \quad \bar{\mu}_{p}=4.3\left[\frac{\bar{m}_{L}\left(\bar{C}_{o}-\bar{C}_{f}\right) \bar{D}_{L} \bar{\Gamma}}{\bar{k}}\right]^{1 / 4}
$$

where $V$ and $G$ are the growth velocity of the solid/liquid interface and liquid thermal gradient at the solid/liquid interface, respectively. The secondary arm spacing (SDAS), $\lambda_{-}$, can be calculated with: 


$$
\bar{\lambda}_{2}=\bar{\mu}_{S} t_{S}^{1 / 3} \quad \text { with } \quad \bar{\mu}_{S}=5.5\left[\frac{\bar{D}_{L} \bar{\Gamma} \ln \frac{\bar{C}_{f}}{\bar{C}_{o}}}{\bar{m}_{l .}\left(\bar{C}_{o}-\bar{C}_{f}\right)(1-\bar{k})}\right]^{1 / 3}
$$

where $t_{S}$ is the solidification time. The calculated microstructural coefficients of RS5 and IN718 alloys are summarized in Table V. The predicted PDAS and SDAS for RS5 and N718 alloys are shown in Figs. 3 and 4. From Table V and Figs. 3 and 4, it can be concluded that, for similar solidification conditions, the secondary dendrite arm spacing in IN718 alloy is approximately $15 \%$ larger than that in RS5 alloy, while the primary dendrite arm spacing in IN718 alloy is about 15\% smaller than that in RS5 alloy. In Fig. 3, the lower the temperature gradient at the solid/liquid interface, the lower the PDAS.

Table V Microstructural coefficients of RS5 and IN718 alloys

\begin{tabular}{|c|c|c|c|c|}
\hline Alloy Type & $\bar{\mu}_{\mathrm{E}}$ & $\bar{\mu}_{\mathrm{D}}$ & $\bar{\mu}_{\text {PDAS }}$ & $\bar{\mu}_{\text {SDAS }}$ \\
\hline RS5 & $1.89 \times 10^{-6}$ & $2.64 \times 10^{-5}$ & $2.53 \times 10^{-3}$ & $8.15 \times 10^{-6}$ \\
\hline IN718 & $3.05 \times 10^{-6}$ & $2.18 \times 10^{-5}$ & $2.21 \times 10^{-3}$ & $9.69 \times 10^{-6}$ \\
\hline
\end{tabular}

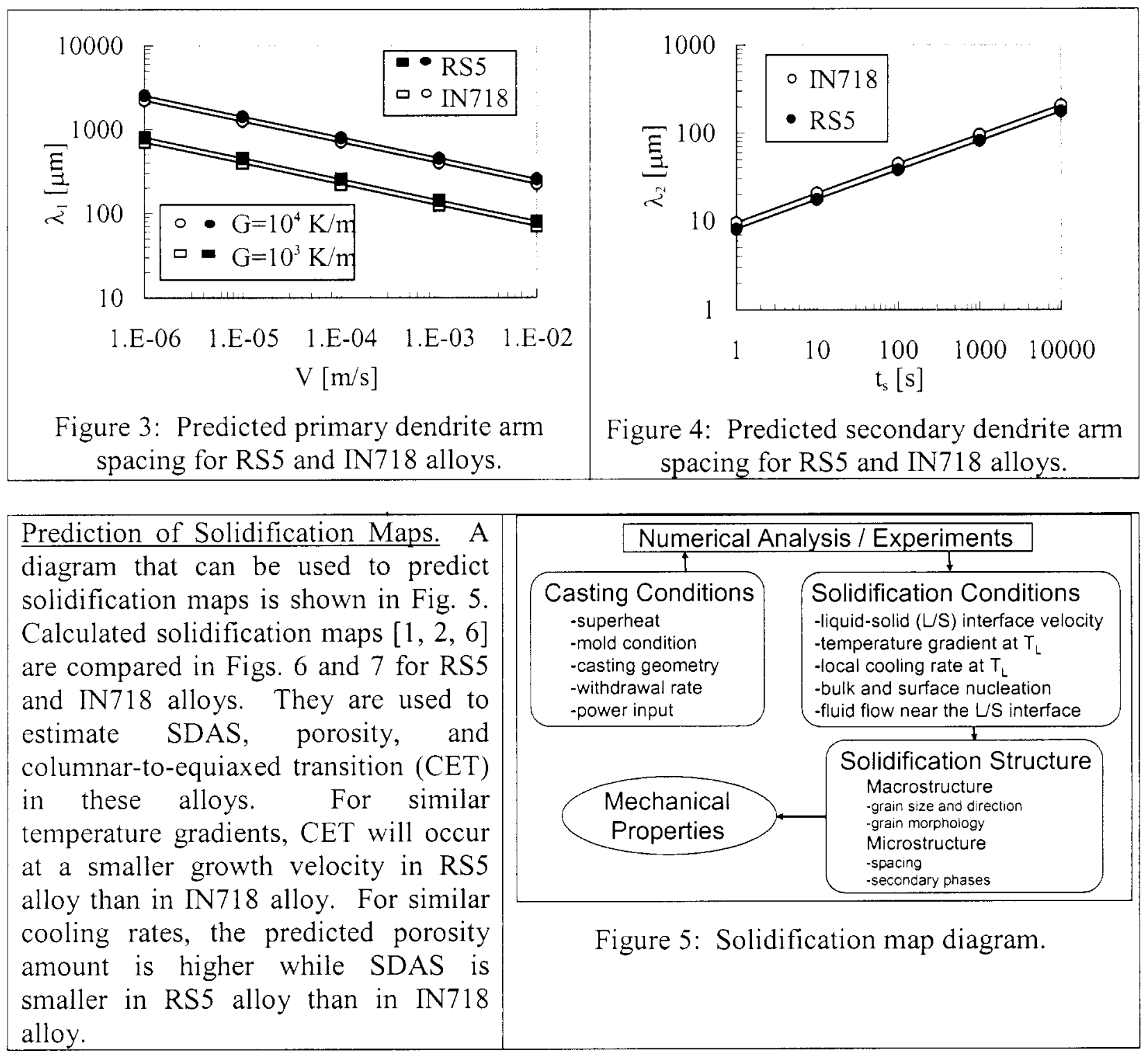




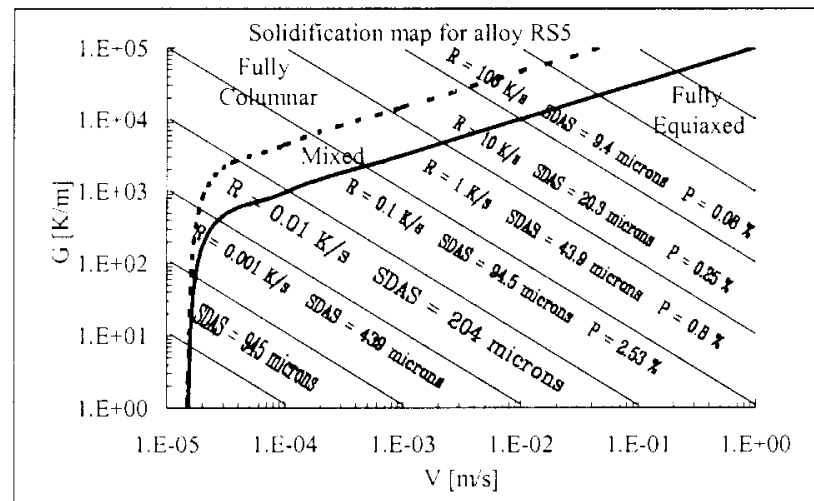

Figure 6: A solidification map for the RS5 alloy.

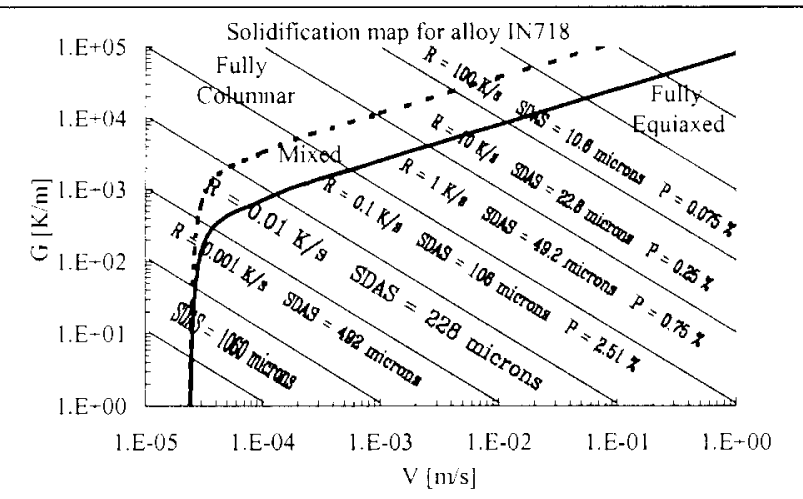

Figure 7: A solidification map for the IN718 alloy.

\section{Mesoscale Modeling of Microstructure of RS5 Alloy}

A recent modeling approach described in details in Ref. [7] was applied to simulate the solidification structure and segregation evolution in RS5 alloy. Some applications of this model are presented in Refs. [8, 9]. The mesoscale stochastic model is based on an EulerianLagrangian tracking method for the solid/liquid interface on a fixed Cartesian grid. The simulation code is named MESO-2D and runs on a PC platform. The purpose of performing the present simulations was to determine the controlling factors for CET, grain size, and the amount of $\mathrm{Nb}$ segregation in thin wall RS5 castings. Figures 8 and 9 show the mesoscale simulations for the thin wall RS5 castings. It was found that a grain density, $G_{E}=5 \times 10^{8} \mathrm{nuclei} / \mathrm{m}^{2}$ is required to obtain a fully equiaxed casting (see Fig. 8). The black color in Fig. 8a shows the potential location of the solidification shrinkage.

The arm spacing selection and evolution of $\mathrm{Nb}$ concentration can clearly be seen in Fig. 9 for a thin wall ( $1 \mathrm{~mm} \times 2 \mathrm{~mm}$ ) RS5 casting. In this case, a $G_{E}=5 \times 10^{6}$ nuclei $/ \mathrm{m}^{2}$ was used in order to achieve a complete columnar structure (see Fig. 8a). The PDAS in Fig. 9 varies from an initial value of approximately $100 \mu \mathrm{m}$ to a final value of about $150 \mu \mathrm{m}$ at the end of solidification. Similarly, SDAS varies from an initial value of about $30 \mu \mathrm{m}$ to a final value of about $50 \mu \mathrm{m}$ (See Fig. 9). Figure 9 also shows the time-evolution of $\mathrm{Nb}$ segregation in these castings. Here, $\mathrm{Nb}$ strongly segregates from the surface to the center of the casting. Thus, Laves phases that are rich in $\mathrm{Nb}$ could easily form at the end of solidification in these castings.

\section{Numerical Simulation of the Bar Casting Experiments}

In-house simulations and experiments were performed to determine a window of process and material parameters for obtaining the optimum microstructure (including secondary phases and CET) in the TCS processed RS5 and IN718 castings. Bar casting experiments were designed to characterize the microstructure formation in thin wall castings during withdrawal and solidification. Figure 10a shows the stereo-lithography (STL) model of a bar casting used in the current simulations. Figure $10 \mathrm{~b}$ describes the STL geometry of the final design used for performing the bar casting experiments.

ProCAST withdrawal simulations (including radiation computations) of the bar casting experiments were performed to provide thermal data for microstructure predictions. Figures 11 to 14 show some of the results of this effort. The solidification time of the simulated bar castings with a withdrawal rate (W) of $1.4 \times 10^{-4} \mathrm{~m} / \mathrm{s}$ is about twice of the bar castings simulated without withdrawal (see Figure 11). Cooling rates in the mush were very similar for both types of withdrawal conditions while the mushy-zone thermal gradients for the bar casting with withdrawal were about one-half of the one without withdrawal. 


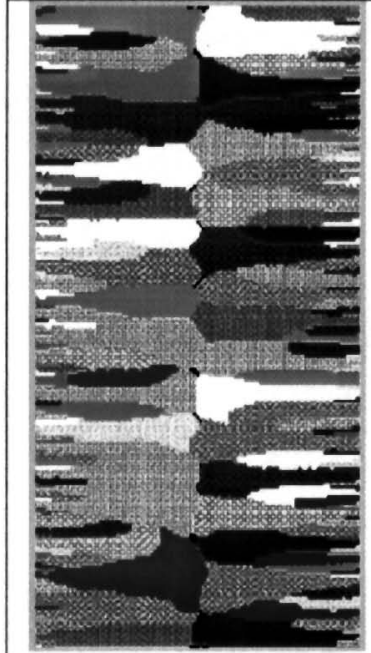

(a)

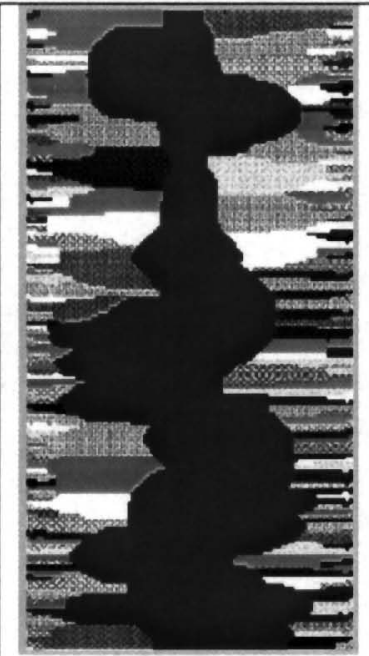

(b)

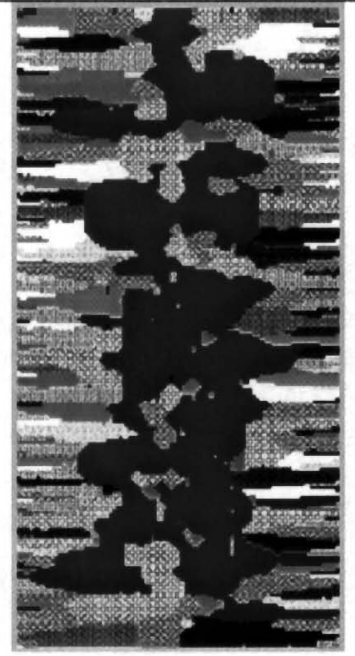

(c)

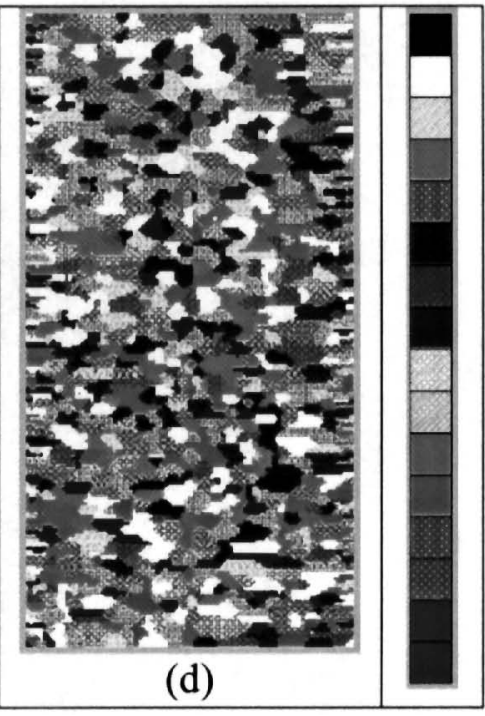

(d)

Figure 8: Simulated solidification structures of thin wall (1 $\mathrm{mm} \times 2 \mathrm{~mm}$ ) RS5 castings: (a) $G_{E}=$ $5 \times 10^{6}$ nuclei $/ \mathrm{m}^{2}$; (b) $G_{E}=1 \times 10^{7}$ nuclei $/ \mathrm{m}^{2}$; (c) $G_{E}=2 \times 10^{7}$ nuclei $/ \mathrm{m}^{2}$; (d) $G_{E}=5 \times 10^{8}$ nuclei $/ \mathrm{m}^{2}$. The colors in the legend show the dendrite crystallographic orientation.

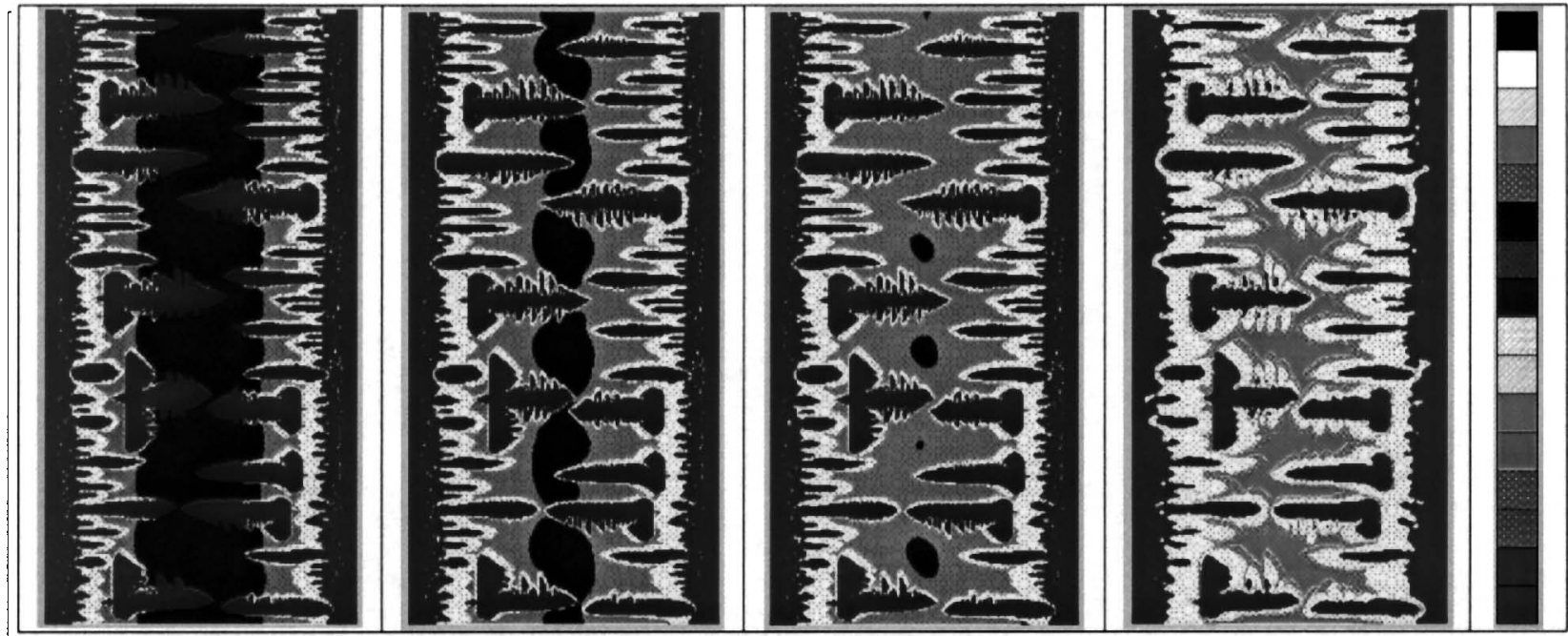

Figure 9: Evolution of $\mathrm{Nb}$ concentration in a thin wall (1 $\mathrm{mm} \times 2 \mathrm{~mm}) \mathrm{RS} 5$ casting $\left(G_{E}=5 \times\right.$

$10^{6}$ nuclei $/ \mathrm{m}^{2}$ ). The colors in the legend show the nondimensional $\mathrm{Nb}$ concentration.

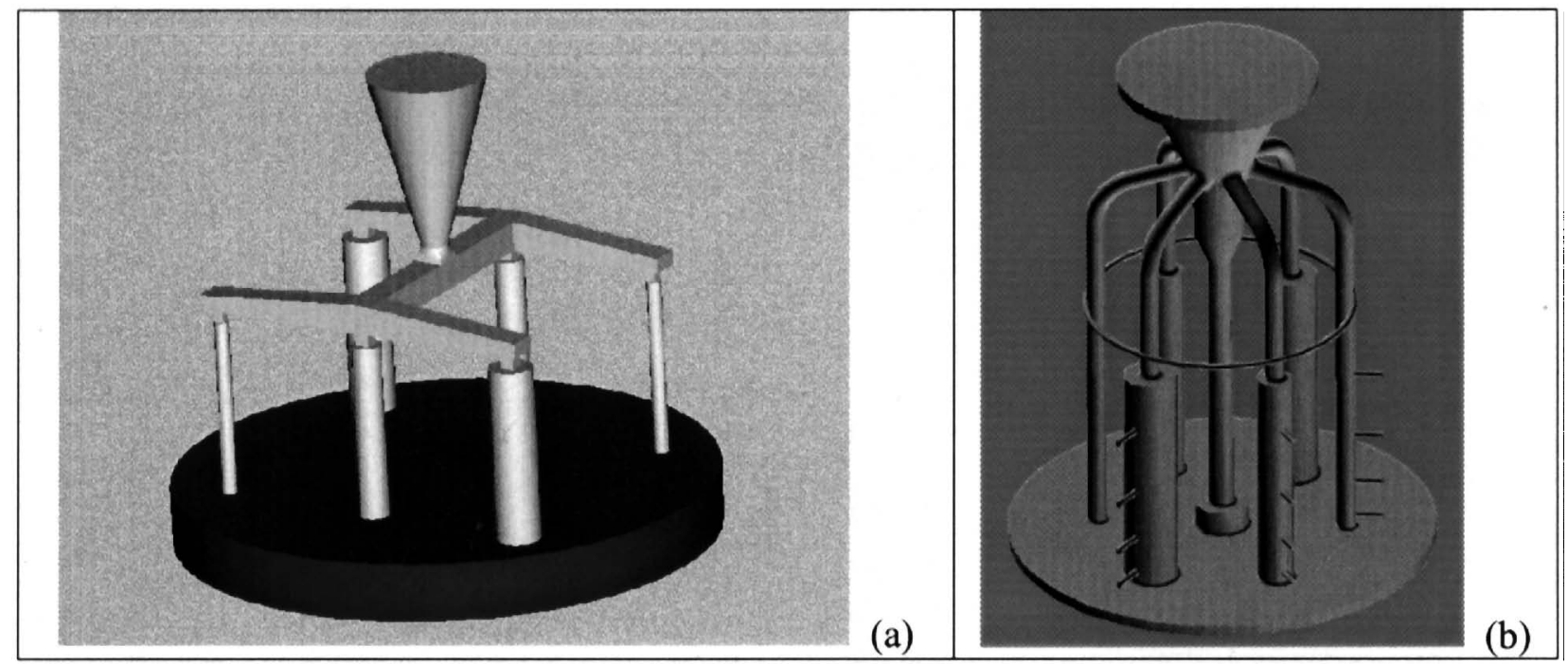

Figure 10: STL geometry of a bar casting: (a) initial design and (b) final design. 


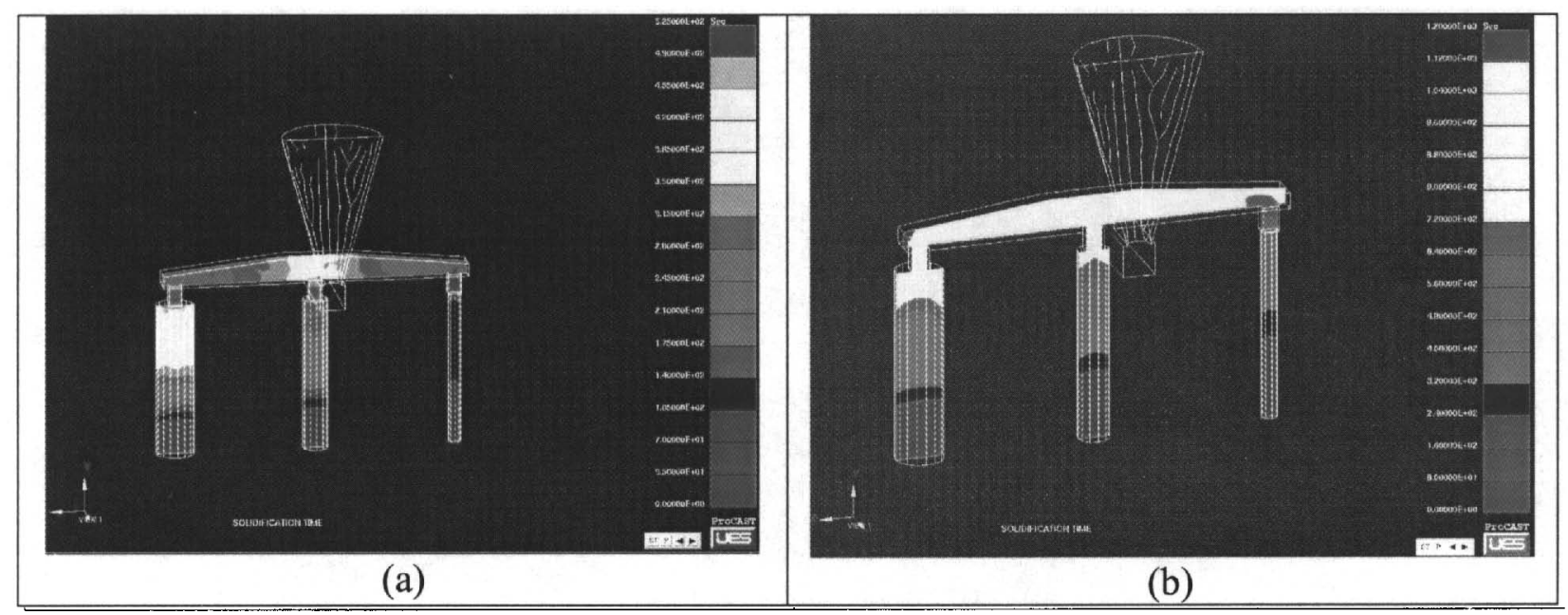

Figure 11: Comparison of computed local solidification time maps in an IN718 bar casting (a) without withdrawal and (b) with a withdrawal rate of $1.4 \times 10^{-4} \mathrm{~m} / \mathrm{s}$. The legends show the local solidification time, which varies for (a) from 0 to $525 \mathrm{sec}$ and for (b) from 0 to $1200 \mathrm{sec}$.

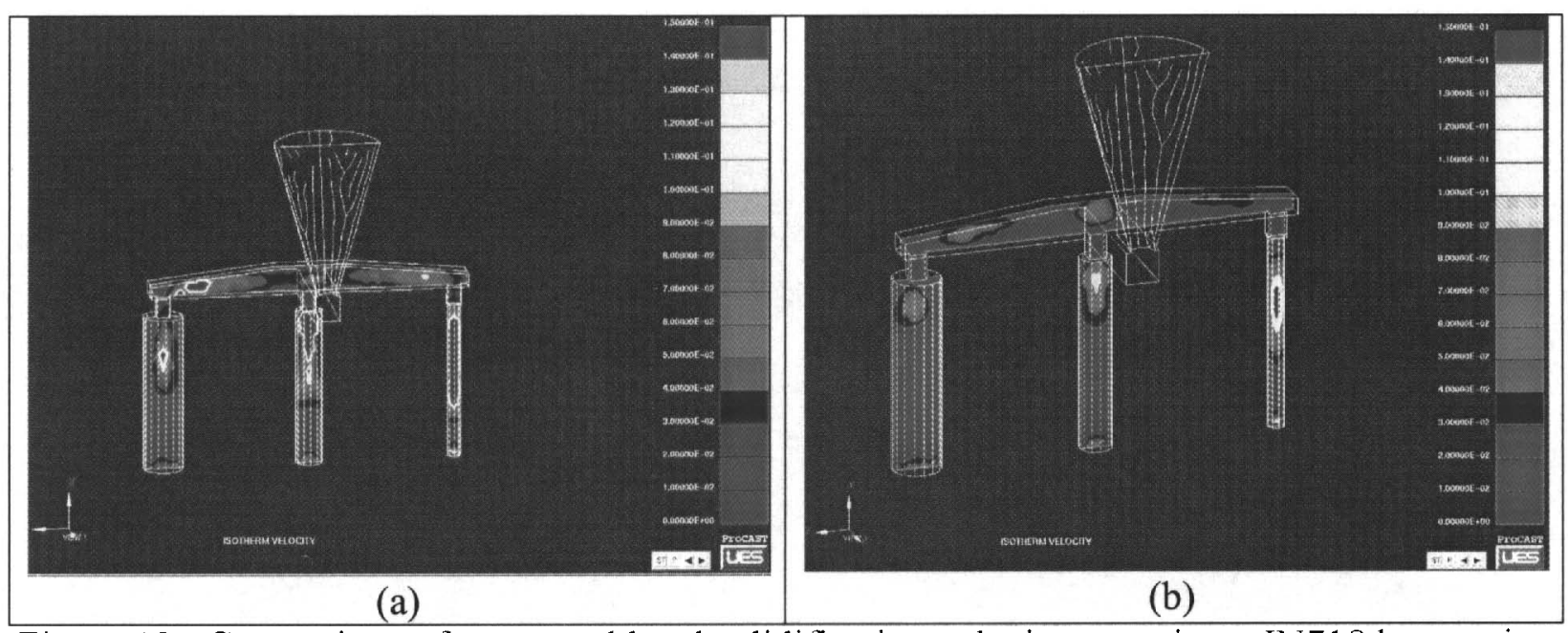

Figure 12: Comparison of computed local solidification velocity maps in an IN718 bar casting (a) without withdrawal and (b) with withdrawal (withdrawal rate of $1.4 \times 10^{-4} \mathrm{~m} / \mathrm{s}$ ). The legends show the values of solidification velocities, which vary from 0 to $0.15 \mathrm{~m} / \mathrm{s}$.

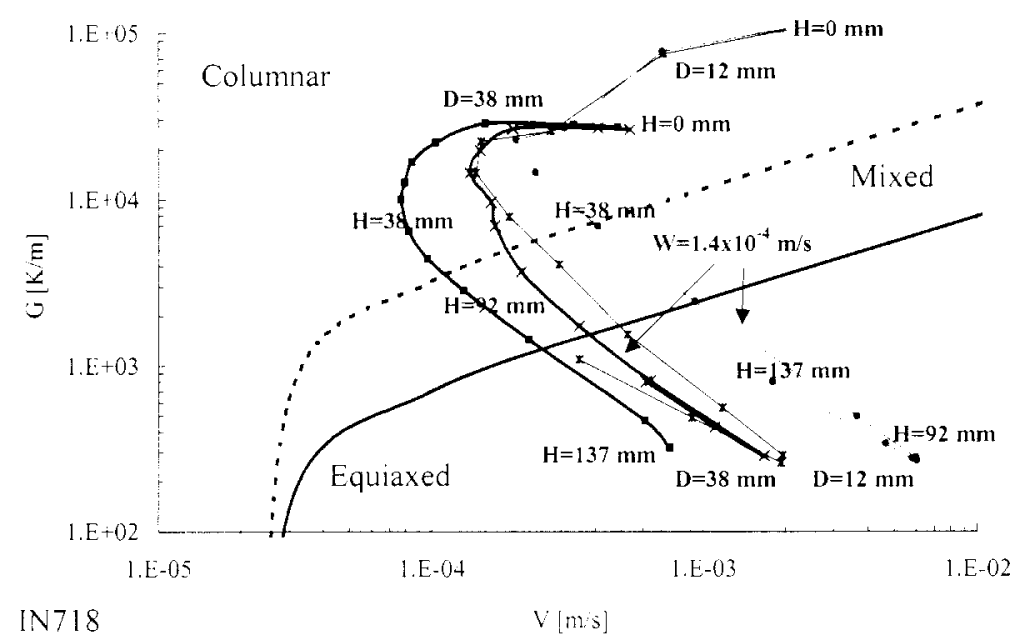

Figure 13: Predicted CET for $\mathrm{IN} 718$ bar castings. 


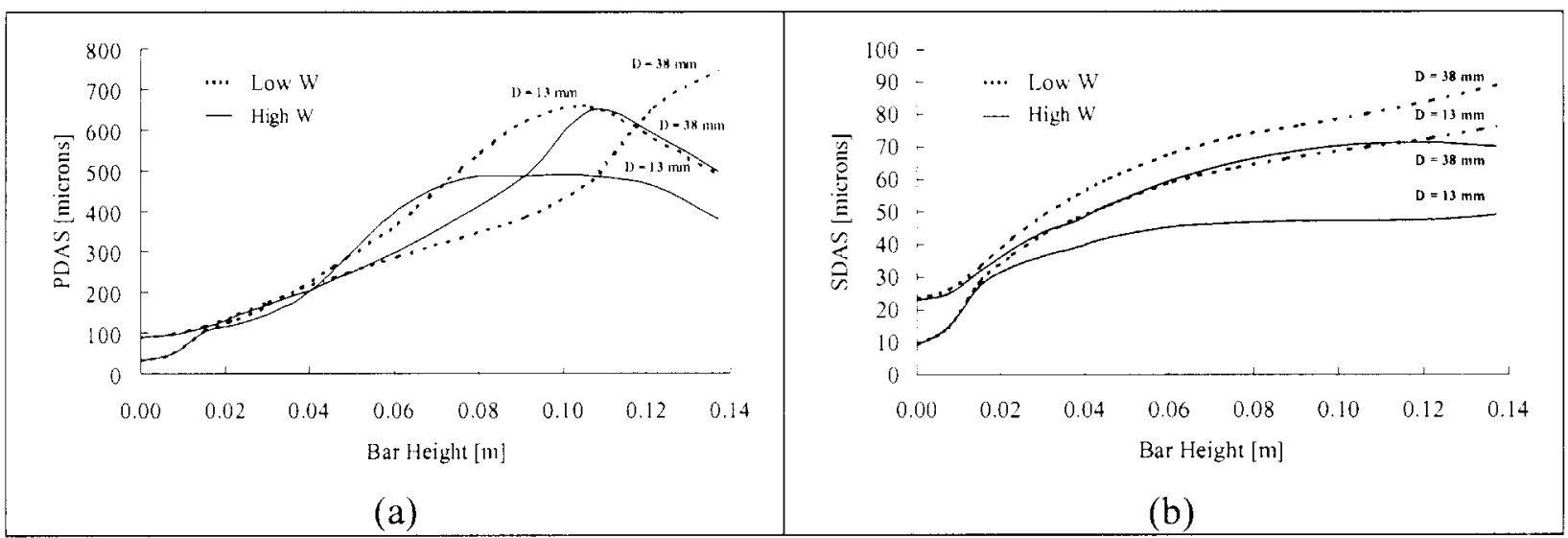

Figure 14: Predicted primary (a) and secondary (b) dendrite arm spacings in IN7 18 bar castings.

Thus, the solidification front velocity of the simulated bar castings with a withdrawal rate of $1.4 \times 10^{-4} \mathrm{~m} / \mathrm{s}$ is about twice of that of the bar castings simulated without withdrawal (see Figure 12). From Figs. 11 to 14 it can be concluded that the withdrawal rate has a significant effect on the solidification structure of these superalloys. For example, a high withdrawal rate favors CET formation in TCS-processed IN718 alloy.

\section{Experimental Work and Comparison of Experimental and Calculated SDAS Values}

Results from a DTA investigation for the RS5 alloy are presented in Figure 16 for two cooling rates. The temperature values in Fig. 15 are for the liquidus, carbide, and solidus (or Eutectic-Laves- phase) temperatures. Figure 17 presents a SEM micrograph of an as-cast RS5 sample continuously cooled from the liquid at $1 \mathrm{~K} / \mathrm{min}$. The solidification and postsolidification phases that were found in the as-cast RS5 sample shown in Fig. 16 were: $\gamma$-phase, eutectic-Laves, Laves, MC-type carbides, porosity, $\delta$-phase, eutectic- $\delta, \gamma$ ', and $\gamma$ '. Table VI shows the chemical composition of some of these phases. Thus, by using DTA measurements and techniques for metallographic characterization, it was demonstrated that secondary phases (carbides and Laves phases) are formed in both alloys. Also, similar solidification paths occur in both alloys. The DTA measurements have also confirmed some of the theoretical calculations of the solidification characteristics of these superalloys.

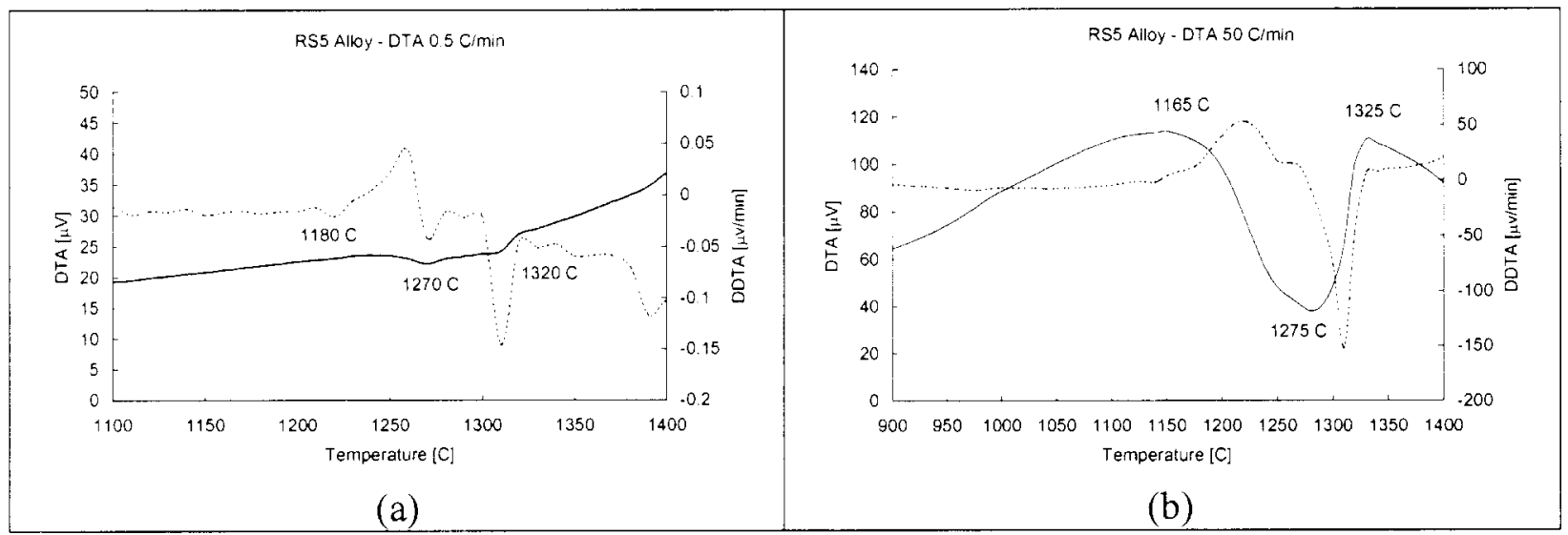

Figure 15: DTA analysis for RS5 alloy: (a) small cooling rate $(0.5 \mathrm{~K} / \mathrm{min})$ and (b) large cooling rate $(50 \mathrm{~K} / \mathrm{min})$. 
Figure 17 presents a comparison of calculated and experimental values of SDAS. The SDAS was measured from the DTA samples and the solidification time for the experimental data was calculated from the cooling rates of the DTA samples and the solidification interval. In Fig. 17, SDAS was calculated with Eq. (7), i.e., $\bar{\lambda}_{2}=\bar{\mu}_{S} t_{S}^{1 / 3}$, where $\bar{\mu}_{s}=8.15 \times 10^{-6}$. Note the good match between the experimental and the calculated results in Fig. 17.

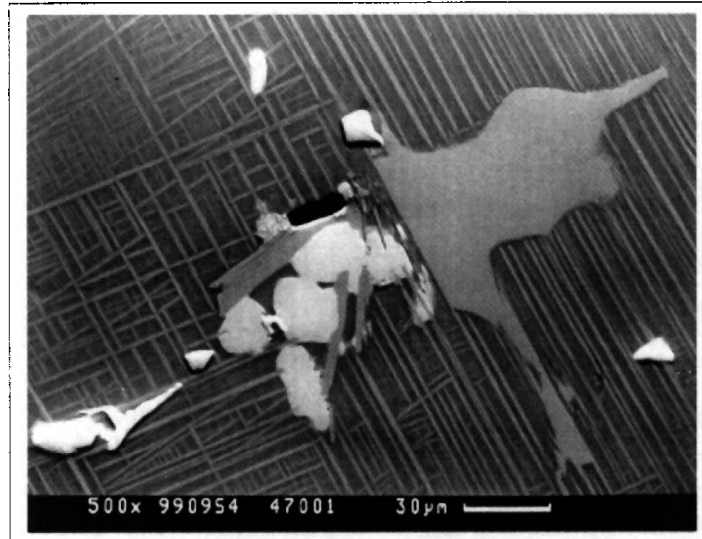

Figure 16: SEM micrograph of an ascast RS5 sample continuously cooled from the liquid at $1 \mathrm{~K} / \mathrm{min}$.

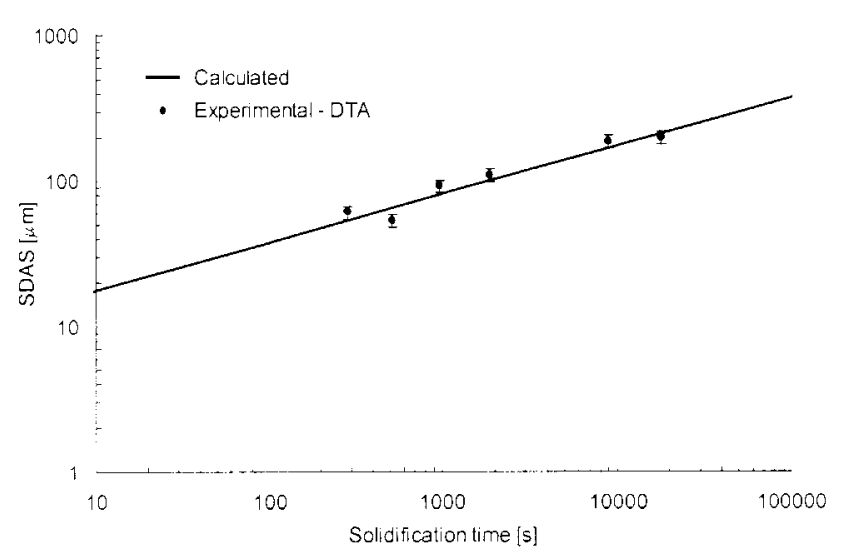

Figure 17: Comparison of predicted and experimental (DTA) SDAS for RS5 alloys.

Table VI Chemical composition of phases in as-cast RS5 by EDS (wt. \%)

(DTA sample-cooling rate of $1 \mathrm{~K} / \mathrm{min}$ ).

\begin{tabular}{|c|c|c|c|c|c|c|}
\hline Element & $\gamma$ matrix & "Carbide" & Eutectic $\delta$ & Laves & Bulk & RS-5 \\
\hline $\mathrm{Ni}$ & 59.96 & 4.53 & 59.99 & 33.02 & 57.65 & 57.40 \\
\hline $\mathrm{Cr}$ & 16.45 & 1.49 & 4.27 & 19.19 & 15.95 & 16.00 \\
\hline $\mathrm{Co}$ & 11.02 & 0.62 & 9.37 & 11.59 & 10.55 & 10.00 \\
\hline $\mathrm{Nb}$ & 1.86 & 49.83 & 11.81 & 15.69 & 4.04 & 4.70 \\
\hline $\mathrm{Ta}$ & 1.20 & 14.53 & 2.67 & 0.72 & 2.26 & 1.40 \\
\hline $\mathrm{Mo}$ & 3.30 & 8.30 & 3.14 & 16.34 & 4.84 & 4.90 \\
\hline $\mathrm{W}$ & 3.66 & - & 2.16 & 1.78 & 1.25 & 2.00 \\
\hline $\mathrm{Ti}$ & 2.08 & 18.23 & 5.74 & 1.29 & 2.65 & 2.70 \\
\hline $\mathrm{Al}$ & 0.31 & - & - & - & 0.50 & 0.90 \\
\hline $\mathrm{Si}$ & 0.16 & 2.48 & 0.85 & - & 0.32 & - \\
\hline
\end{tabular}

\section{Concluding Remarks}

Current theoretical calculations have revealed the following: (a) the secondary dendrite arm spacing in cast $\mathrm{IN} 718$ alloy is approximately 15\% larger than that in cast RS5 alloy, while the primary dendrite arm spacing in cast $\mathrm{IN} 718$ alloys is about $15 \%$ smaller than that in cast RS5 alloy; (b) the main contributing elements in descending order for the growth of the primary phase based on the constitutional undercooling parameter are (i) for $\mathrm{IN718:} \mathrm{Nb}, \mathrm{Ti}, \mathrm{Cr}, \mathrm{Mo}$, and $\mathrm{Al}$ and (ii) for RS5: $\mathrm{Nb}, \mathrm{Ti}, \mathrm{Co}, \mathrm{Mo}, \mathrm{Cr}$, and $\mathrm{Al}$; (c) the overall constitutional undercooling parameter of RS5 is about twice that of IN718 alloy, meaning that RS5 might be more susceptible than $\mathrm{N} 718$ to the formation of solidification-related defects; and (d) withdrawal rate has a significant effect on the solidification structure of these superalloys. 
In-house experiments were performed to determine a window of process and material parameters for obtaining the optimum microstructure (including secondary phases and columnar-to-equiaxed transition) in the TCS processed RS5 and IN718 castings. By using DTA measurements and techniques for metallographic characterization, it was demonstrated that secondary phases (carbides and Laves phases) are formed in both alloys. Also, similar solidification paths occur in both alloys. The DTA measurements have also confirmed some of the theoretical calculations of the solidification characteristics of these superalloys.

\section{Acknowledgements}

This work was conducted by the National Center for Excellence in Metalworking Technology (NCEMT), operated by CTC under contract No. N00014-00-C-0544 to the U.S. Navy as part of the U.S. Navy Manufacturing Technology Program. Mr. T. C. Kiesling from $C T C$ is acknowledged for performing ProCAST simulations of the bar castings under various withdrawal conditions. Mr. R. J. Henry from CTC is acknowledged for his useful comments and suggestions in writing this article.

\section{References}

1. L. Nastac, J. S. Chou, and Y. Pang, "Assessment of Solidification-Kinetics Parameters for Titanium-Base Alloys," (Paper presented at the International Symposium on Liquid Metals Processing and Casting, Vacuum Metallurgy Conference, Santa Fe, NM, February 21-24, 1999), 207-233.

2. L. Nastac, Y. Pang, and C. E. Shamblen, "Estimation of the Solidification Parameters of Titanium Alloys," (Paper to be presented at the $105^{\text {th }}$ Casting Congress, April 28 - May 1, 2001), to appear in AFS Transactions, 2001.

3. L. Nastac, J. J. Valencia, T. C. Kiesling, M. L. Tims, S. B. Shendye, and M. L. Gambone, "Advances in Solidification of Thin Wall Superalloy Castings," (Paper presented at the Symposium on Superalloy Processing, TMS Fall Meeting, Cincinnati, OH, 1999).

4. W. J. Boettinger, U. S. Kattner, S. R. Coriell, Y. A. Chang, B. A. Mueller, "Development of Multicomponent Solidification Micromodels using a Thermodynamic Phase Diagram Data Base," (Paper presented at the Modelling of Casting, Welding and Advanced Solidification Processes VII Conference, Eds. M. Cross and J. Campbell, TMS, London, England, September 10-15, 1995), 649-656.

5. H. P. Wang, J. Zou, E. M. Perry, L. R. Kaisand, and R. Doherty, "Micro-Macro modeling of the Investment Casting of Multi-Component Superalloys," (Paper presented at the Modeling of Casting, Welding and Advanced Solidification Processes-VI Conference, Eds. T. S. Piwonka, V. Voller, and L. Katgerman, TMS, Palm Coast, Florida, 1993), pp. 45-53.

6. J. D. Hunt, "Steady State Columnar and Equiaxed Growth of Dendrites and Eutectic," Material Science and Engineering, 65 (1984), 75-83.

7. L. Nastac, "Numerical Modeling of Solidification Morphologies and Segregation Patterns in Cast Dendritic Alloys," Acta Materialia, 47 (17) (1999), 4253-4262.

8. L. Nastac, Keynote Lecture: "A New Stochastic Approach for Simulation of Solidification Morphologies and of Segregation Patterns in Cast Dendritic Alloys," (Paper presented at the International Conference on Modeling of Casting and Solidification Processes (MCSP-4), Eds. C. P. Hong, J. K. Choi, and D. H. Kim, Yonsei University, Seoul, Korea, September 5-8, 1999), $31-42$.

9. L. Nastac, "A Stochastic Approach for Simulation of Solidification Morphologies and Segregation Patterns in Cast Alloys," (Paper presented at the Modelling of Casting, Welding, and Advanced Solidification Processes-IX conference, United Engineering Foundation, Eds. P. R. Sahm, P. N. Hansen, and J. G. Conley, Shaker Verlag, Aachen, Germany, August 20-25, 2000), 497-504. 